\title{
The sleeping-bag landscape
}

\section{Rowan Bailey and Claire Barber}

\begin{abstract}
This essay considers the 'sleeping-bag' as a travelling concept for developing new relations between the landscape and textiles. It examines the sleeping-bag within the wider historical and cultural contexts in which the material qualities of cloth are carried and transformed. By examining the appearance of the sleeping-bag in different landscapes and its own structure as a vehicle for conceptual thinking, the essay considers how certain strategies of thinking-through-making are brought to the fore in the analysis of specific examples, from an examination of the interconnectedness between materials and the landscapes from which they derive to the distancing of this relation as the sleeping-bag travels through unfamiliar terrains and climates. In turn, this cultural analysis provides the framework for The Sleepingbag Project, which was first developed in 2010 and which uses the tools and skills of craft to reveal unacknowledged and hidden identity relations between craft-making and homelessness. It is argued that through this project an identity of place for the displaced is made possible in and through an ethics of care.
\end{abstract}

\section{Concepts that travel}

A sleeping-bag has a distinctive structure. It preserves life in extreme circumstances by capturing air through down or synthetic fibres and re-insulating the body using excess body heat. Its contemporary examples are high-tech, branded by names such as Polarguard $\AA$, PHD, ALPKIT, Rab®, Cumulus and VAUDE, although its long and muddled history belies this sophistication. As a place holder for identities past and present, the sleeping-bag becomes a container for the embodiment of these histories, including the histories of its own making. To explore the sleeping-bag as a travelling concept in different fields, it is worth mentioning the theoretical backdrop presented in the writings of Meike Bal, author of Travelling Concepts in the Humanities: A Rough Guide (2002). This book offers a theoretical platform for thinking in, with and through the sleeping-bag, in the context of cultural analysis. What is interesting about Bal's work is the metaphorical resonance of the landscape as a terrain within the practice of text-based research. Concepts engage with and are shaped by aspects of cultural production across space and time. In the introduction, Bal provides an account of the interdependent relationship between objects and the concepts derived from them: 
The field of cultural analysis is not delimited, because the traditional delimitations must be suspended; by selecting an object, you question a field. Nor are its methods sitting in a toolbox waiting to be applied; they, too, are part of the exploration ... this is where travel becomes the unstable ground of cultural analysis. (2002: 4)

In effect, the object of analysis contributes to the formation of a conceptual framework for understanding the phenomena of cultural life, its practices, contexts, dialogical interplays with other 'things' and its reception within the field of discourse. In the spirit of Bal's travel through modes of cultural analysis, and taking on board her valuable insights into their transdisciplinary potential, this essay proposes to reconfigure the existing delimitations of craft as a selfcontained object. An investigation of how the sleeping-bag travels, literally and metaphorically, is a method of shedding light on the meaningful practice of craft within the social fabric of the world. The landscapes within which it appearsits material composition, the conflicts between intimacy and distance, and the associative triggers between examples-form a route map through this essay.

We propose to firstly address the 'sleeping-bag' as a travelling concept for forging new relations between the landscape and textiles. The sleeping-bag serves as place holder for identities past and present through its material resonance in the landscape. We will consider how the sleeping-bag appears in different historical and cultural contexts, from its early incarnation in Turkey, Iran, Afghanistan, Mongolia and southern Russia; its use by explorers in Antarctica; to its mass production and circulation in times of military conflict. These examples address how the design and manufacture of sleeping-bags is often dictated by the conditions and demands of specific terrains.

Secondly, by turning the positioning of the sleeping-bag on itself, what does it mean to consider this item as a landscape of and for the maker and to focus on those specific strategies of empathic and ethical thinking and making that take place through material encounters with cloth? As a case study, The Sleepingbag Project, which was developed and based in Bradford, uses the tools and skills of craft to reveal unacknowledged and hidden materialities of exchange between the maker and homelessness. We address this project's attempts to facilitate the empathic imagination through the act of craft-making and, in so doing, reconfigure an understanding of identity relations within the urban landscape. We argue that this creates conditions of possibility for crafting an identity of place for the displaced and thus reclaim the urban landscape, in and through an ethics of care. 


\section{Materials in and of the landscape}

Early iterations of the sleeping-bag appear in the landscapes of Turkey, Iran, Afghanistan, Mongolia and southern Russia with the felt kepenek, a garment derived from fleece. Using heat, water and pressure to bond fibres into a solid mass, felt is moulded and shaped into body pods. Since the Middle Ages, this cocoon cloak, designed by Yörük tribespeople, has served in extreme climates as portable architecture for the body. As this style of sleeping-bag suggests, the significance of sleeping-bag formations derived from the landscape extends to the material resources required and how they are constructed.

Nomadic tribespeople of Mongolia (Mongol and Kazakh), Iran (Turkmen and Kurdish), Afghanistan (Uzbek and Tajik) and Russia (Kazakh, Turkmen and Tartar) endure extreme climates. For example, the soil type that results from dry climates cannot sustain large flocks of sheep for long, which requires the movement of flocks in search of new pastures. The felt cloak of the herdsmen is created from the fleece of the herd and is a solution to maintaining the nomadic lifestyle. In Mongolia, for instance, horses drag a wooden pole wound round with sheep's fleece across the ground so as to create enough friction to form a firm felted material. The success of these communities is linked to the tough, warm and transportable body pods that are fashioned out of this felt. Thus, the craft of making felt is intimately linked to the maker's livelihood and their understanding of a given climate and terrain.

Similarly, reindeer fur has also been used in the manufacture of body pods. Reindeer fur can have up to 2,000 hollow hairs per centimetre, and this volume has unique insulating properties. Prior to the arrival of Euro-Americans, the traditional Koyukon people of Alaska perfected insulated clothing and sourced the skins of animals that live in the northern landscapes of Alaska.

The resources required to create a felt cloak consist of fleece, water, person power and heat. Felt construction is dependent on the specific frictional properties of wool. Each fibre is covered by small scales, which protrude at an angle so that, when they move against one another, they become interlocked (Belgrave 2001). A mass of fibres, moving together under pressure, become tightly linked and then matted to produce felt. The type and quantity of materials used can be traced to their source. A type of felt cloak used by Turkmen requires three kilograms of fleece, which can be obtained from the fleece of approximately three sheep. The wealth of nomadic communities was traditionally determined by the size of their flock, with value systems directly linked to the material resources that are born from and sustained by the landscape (Deffontaines 1967). The type of fleece that is used for the felt comes from specific breeds, such as the Dãglak, a flat-tailed sheep that is indigenous to Iran and the Erik (a Turkmen breed) (Burkett 1971). Heat is required to produce felt and, therefore, its manufacture is closely aligned to the seasons. It is difficult to felt fibres in 
the cold but, equally, the summer temperatures present problems due to the physical exertion required and the risks of dehydration. As water is a necessary resource for the felt-making process, it takes place in regions with natural sources of water.

The first sleeping-bag to be patented, in 1876, was named the Euklisia rug (British Museum and BBC 2010) and was made from woollen cloth. The materials were sourced in Wales, having been worked by men and women from rural communities (up until the nineteenth century, weaving was centred in rural communities rather than cities). The sheep would have been reared on the hillsides, and most families would have carders and a spinning wheel to transform wool into yarn for weaving. Even though diverse industries on a bigger scale were driven by a more efficient use of water power during the latter stages of the eighteenth century, which could drive machines to card and spin automatically, domestic spinning continued. The invention of the Euklisia rug was a timely entrepreneurial endeavour against the backdrop of increasing colonialism and troops in combat. The Euklisia rug, was exported across the world, with records suggesting that in 1891 the inventor, Pryce Jones, had a contract to supply the Russian army with 60,000 rugs. The rug also found its way to the Australian outback and missionary posts in the Congo (Startzman 2014). Its dispersal across the globe as a 'sleeping-bag' form, through travel and exportation, shows how the transposition and relocation of traditional crafts and materials created in one landscape travels to other terrains and climates.

Felt and reindeer fur continue to be a source of inspiration in contemporary sleeping-bag design. The latest 2013 Nemo Canon -40 Expedition Bag sleepingbag mimics the design of traditional Inuit sleeping-bags, using a construction method that pre-warms air before it is inhaled (Jurries 2013). Gabi Schillig's felt sculptures occupy the urban landscape in a series that mediates relations between public and private, but also privileges a position in the urban landscape, enabled by its contrasting material qualities of felt. This material stands out in the reinforced concrete, metal and glass of urban landscapes (see Figure 1). What differentiates the landscape of the Yörük tribesmen from the urban landscape of conceptual design is clear. Whereas Schillig's felt structures are performance pieces, serving as exemplars of conceptual design in a busy urban city-scape, the felt kepeneks of the Yörük tribesman are living pieces, designed out of necessity and from the landscape itself, and used for shelter against environmental conditions. 


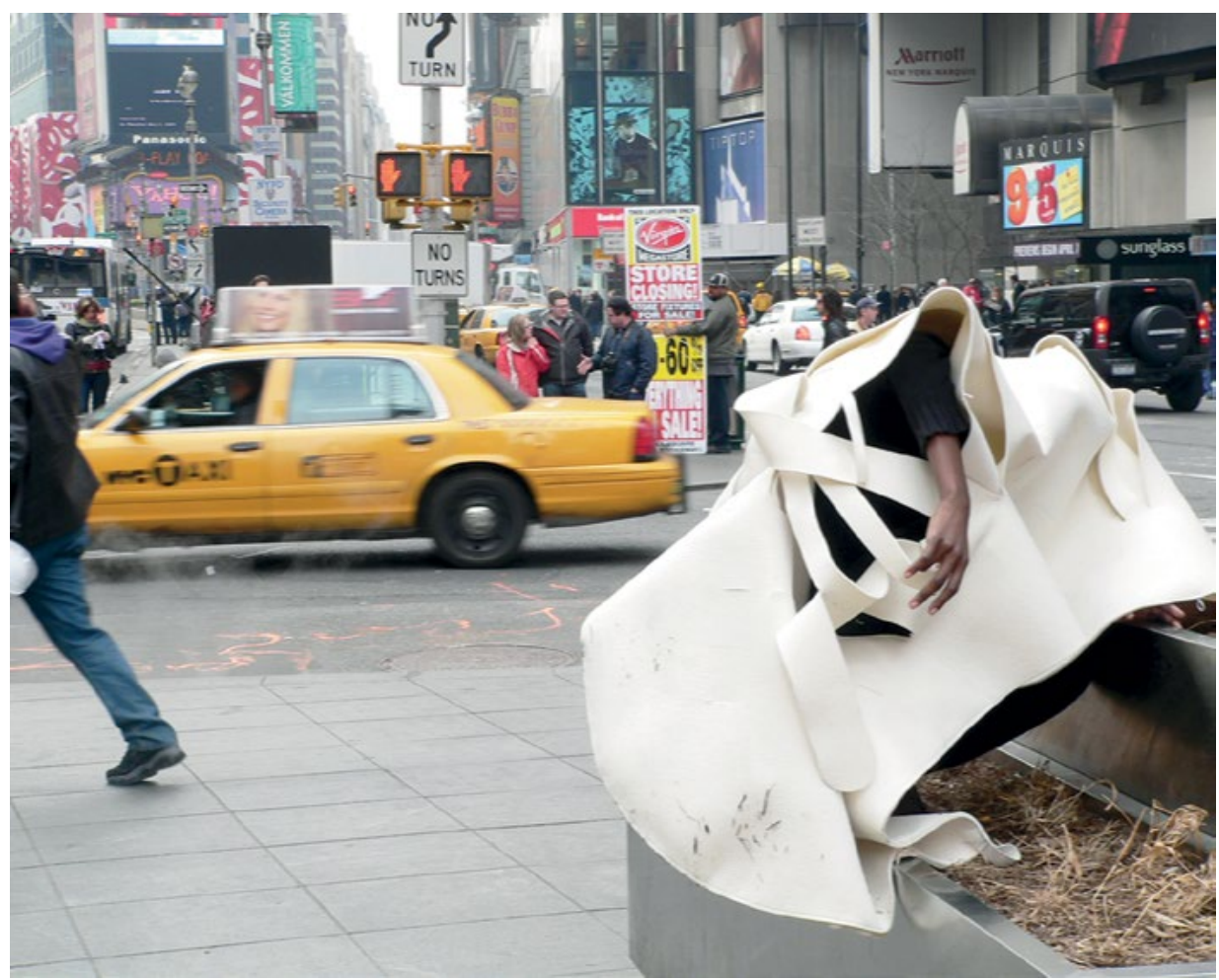

Figure 1: Gabi Schillig, Public receptors, 2009, New York Photo: Courtesy of Gabi Schillig

Whereas in traditional nomadic cultures, materials are intimately connected to the maker's livelihood and their understanding of the landscape for survival, the symbolic significance of these materials and processes changes as they become part of a wider commercial context. Schillig's conceptual work exemplifies this kind of shift in thinking. The body pod is an alienated felt figuration that, while divorced from the environment, offers itself up as a protective shield against some of the harsh conditions of urbanisation. The distancing between materials and the landscape from which they are sourced brings into play a different set of complex negotiations between the user and sleeping-bag systems in the context of moving across unfamiliar terrains.

\section{Materials distanced from the landscape}

Herbert G. Ponting was appointed the official photographer of the Terra Nova Expedition to Antarctica of 1910-13, which was led by Robert Falcon Scott. Among photographs of the landscape of Antarctica, the ship Terra Nova as it negotiates its way through the ice, and the explorers, hut-bound waiting for spring, is an image of crew members repairing reindeer fur sleeping-bags 
at Cape Evans in May 1911. ${ }^{1}$ The sleeping-bag appears intermittently in the historical re-telling of this journey and carries a narrative about the plight of the tragedy itself. Two specific examples, when juxtaposed, reveal the material structure and complexities of sleeping-bags as they travel through the Antarctic.

The first example is recorded in Apsley Cherry-Garrard's diaries, first published in 1922 under the title The Worst Journey in the World: Antarctica (CherryGarrard 1989). Cherry-Garrard writes of his sleeping-bag's inability to cope with the harsh conditions:

The trouble really began in your sleeping-bag, for it was far too cold to keep a hole open through which to breathe. So all night long our breath froze into the skins, and our respiration became quicker and quicker as the air in our bags got fouler and fouler: it was never possible to make a match strike or burn inside our bags! (1989: 186)

Elsewhere he writes of getting frostbitten inside the bag and the extreme discomfort at night time when they would become 'obstinate coffins' (1989: 255). The second example is part of the reception of the expedition in popular culture, with Ealing Studios' 1948 Technicolor production Scott of the Antarctic, featuring John Mills. In an early scene at base camp, Ponting, played by the actor Clive Morton, entertains his companions with a tonguetwisting poem he names 'The sleeping-bag poem'. It is a performance that demonstrates the changeable qualities of reindeer fur and skin. As an object of humour and optimism, the poem presents the reindeer hide as a material beyond the explorer's previous experience and focuses on the navigation of the sleeping-bag's surface qualities, while accentuating, through wit and playful gesture, the encumbrance of its form. Ponting confuses his audience through his frantic and oscillating tongue-twisting commentary:

Some likes the skin side on the inside and the fur side on the outside others like the skin side outside and the fur side on the inside.

If you turn the skin side inside thinking you will side with that side, then the soft sides fur side inside which some argue is the wrong side. If you turn the fur side outside, as you say it grows on that side,

then your outside is next to skin side which for comfort is not the right side.

The skin side is the cold side and your outside is not your warm side and two cold sides side by side are not the right side, one side by side. If you decide to side with that side then turn the top side inside and the other side inside then the cold side hard side skin side will beyond all question be inside out.

1 See 'Petty Officer Evans and Crean mending sleeping bags', Scott Polar Research Institute, www.spri.cam. ac.uk/picturelibrary/catalogue/article/p2005.5.397/. 
The interchangeable character of the sleeping-bag bears an ominous form as it is reshaped through Ponting's performance. In contrast to their limp and passive shape on the knees of the Terra Nova explorers, the sleeping-bag comes alive as a twisted and complex terrain that the explorer has to negotiate. Recto and verso, the skin and fur sides become, as the story unfolds, solid structures that are, according to Cherry-Garrard, capable of asphyxiating the user.

These two examples demonstrate the peculiar distancing of the sleeping-bag's attachment to the landscape as soon as it starts to travel beyond the limits suited to its original function. This detachment brings the landscape and the sleeping-bag into a dichotomous, rather than a complementary and mutually supportive, relation. Whereas the indigenous peoples inhabiting the arctic are connected to the land for survival and thus have developed an ecosystem to manage their environment, 'explorers' have sought to 'master' complex and hostile terrains, and with this, create a demand for new ways to cope with the challenges of self-preservation. This leads one to consider how the sleepingbag starts to travel across the globe, often as a result of colonial and militarised pursuits for land ownership.

The military sleeping-bag, in particular, has a history where adaptation to surroundings is built into the mass manufacture and ideological war propaganda of the bags themselves. A 1916 poster reveals the multi-functional power of the 'Save our Skin' (SOS) sleeping-bag.

The image depicts a gloved British infantryman using a sleeping-bag to protect him as he straddles a barbed wire fence while shaping a piece of wire to form the letters 'SOS'. The image is framed by the caption 'How we strafe German barbed wire':

S.O.S. SLEEPING-BAGS: In addition to being warm and waterproof, when open and thrown across enemy's barbed wire entanglements enable the men to traverse them without receiving a scratch. 


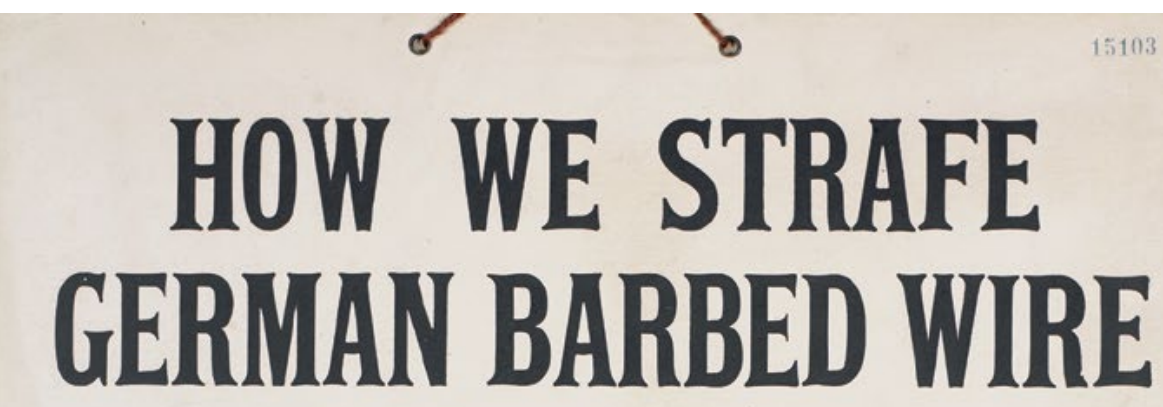

By S.O.S-'Save Our Skin'-Appliances

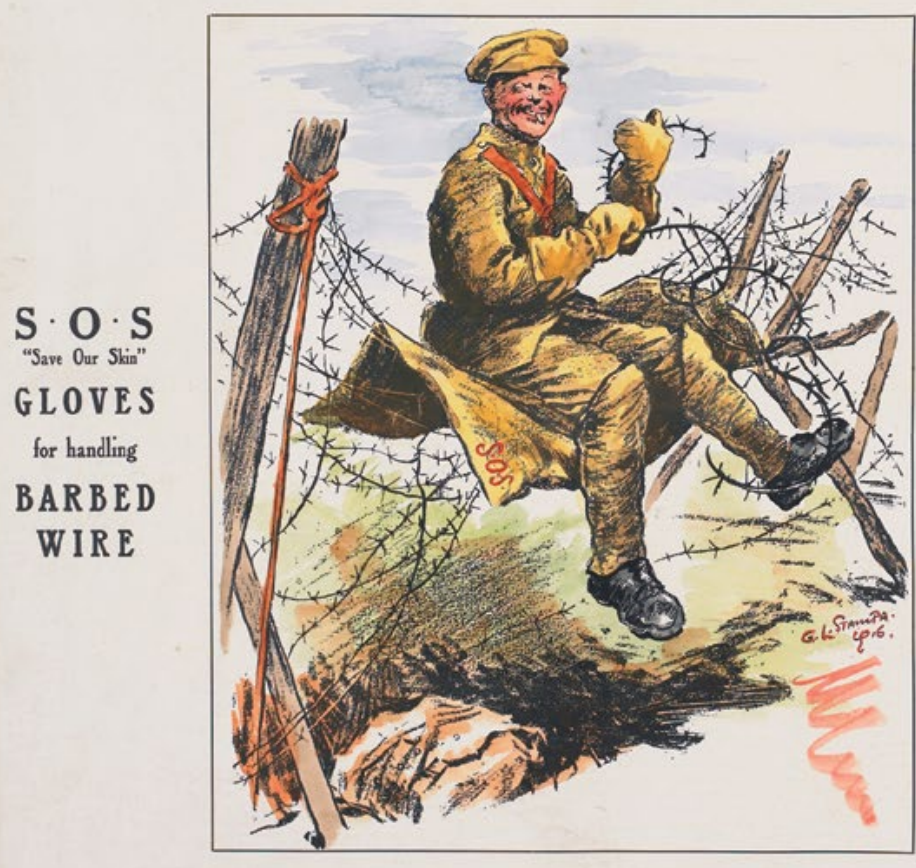

$\mathbf{S} \cdot \mathbf{O} \cdot \mathbf{S}$

"Sare Our Stin"

British Warm

COATS and

Waistcoats

GAITERS

\section{S.O.S SLEEPING BAGS}

In addition to being warm and waterproof, when open and thrown across enemy's barbed wire entanglements enable the men to traverse them without receiving a scratch

Figure 2. George Loraine Stampa, How we strafe German barbed wire:

By S.O.S. - 'Save our Skin' - Appliances, 1916

Photo: Courtesy of Imperial War Museum, London 
The fantasy of this image is directed to an audience unaware of the reality of frontline service during the First World War. The solider, making trench art out of barbed wire while sitting on a well-padded and sturdy sleeping-bag, is a mythic reconstruction. Prior to the Second World War, most kitbags contained bed rolls only. One instance of a sleeping-bag structure in use during the First World War can, however, be found in the archive collection of Dr W.R. Blore, who was part of the Royal Army Medical Corps, based at Suvla Bay, Gallipoli (see Figure 3). As a medical doctor, Blore, of higher rank, and perhaps more stationary than a foot solider of the infantry, was supplied with a kapok-filled bag. A fibre that is often used for stuffing pillows, kapok is harvested from the pods of a tree native to the tropics of West Africa, and parts of southern Mexico and the southern Amazon.

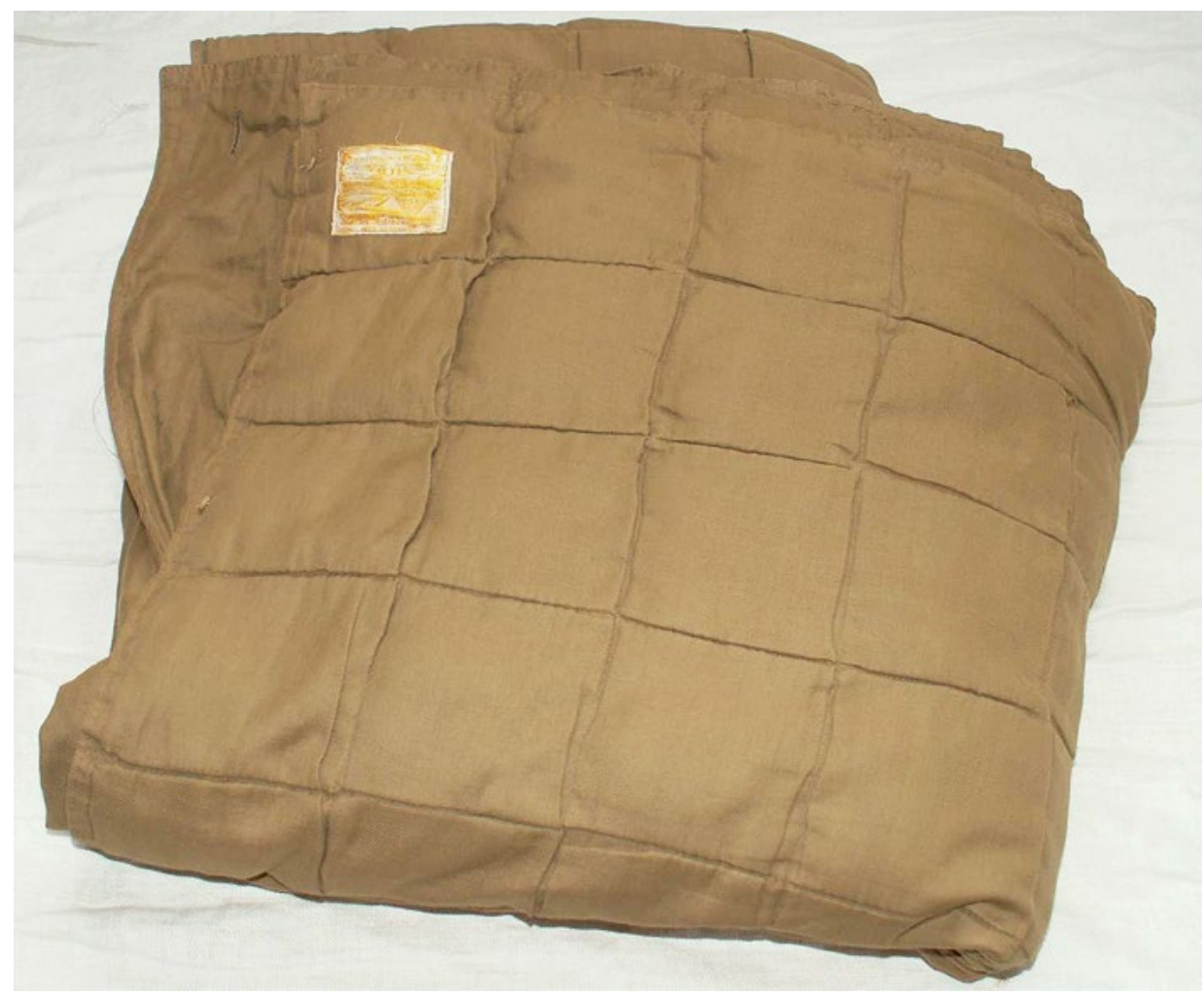

Figure 3. Dr W.R. Blore's kapok-filled sleeping-bag, 1915-18

Photo: Courtesy The Great War Archive, University of Oxford

It was not until the Second World War that sleeping-bags became part of a much larger mass manufacture and distribution of military kit. The US military, in particular, invested heavily in research into thermal clothing and sleepingbags. The Harvard Fatigue Laboratory, founded in 1927 by biochemists L.J. Henderson and Bruce Dill, looked at the physiological effects of heat and cold on the body, by conducting experiments to track the insulation needs of the 
user. In 1942, Dr Harwood Belding created the Copperman, a heated manikin that was designed for the testing of thermal environments. The laboratory's research was put to the test out in the field, in the battles of the Bulge and the Atlantic, for which soldiers were supplied with footwear and protective clothing to cope in different climates and conditions. The result of scientific research at the laboratory was the design and development of new sleeping-bag systems in the postwar period.

In the heat of the Cold War, the sleeping-bag, as a structure, takes on new forms for different climates. America's militarised power can be found in the types of sleeping-bag produced. Referred to as sleeping systems, they contain labels with clear instructions. The Mountain M-1949 Bag (see Figure 4) includes capitalised warning notes such as 'AVOID sweating in bag' and 'Breathe through lace opening ... DO NOT put face inside bag'. These instructions differ with each sleeping-bag system, ranging from the generic model, to the styles named 'Intermediate Cold Weather (ICW)' and 'Sleeping Extreme Cold Weather (ECW)'. The sleeping-bag spectrum thus diversifies as the occupation of different landscapes by military presences shifts and changes over time.

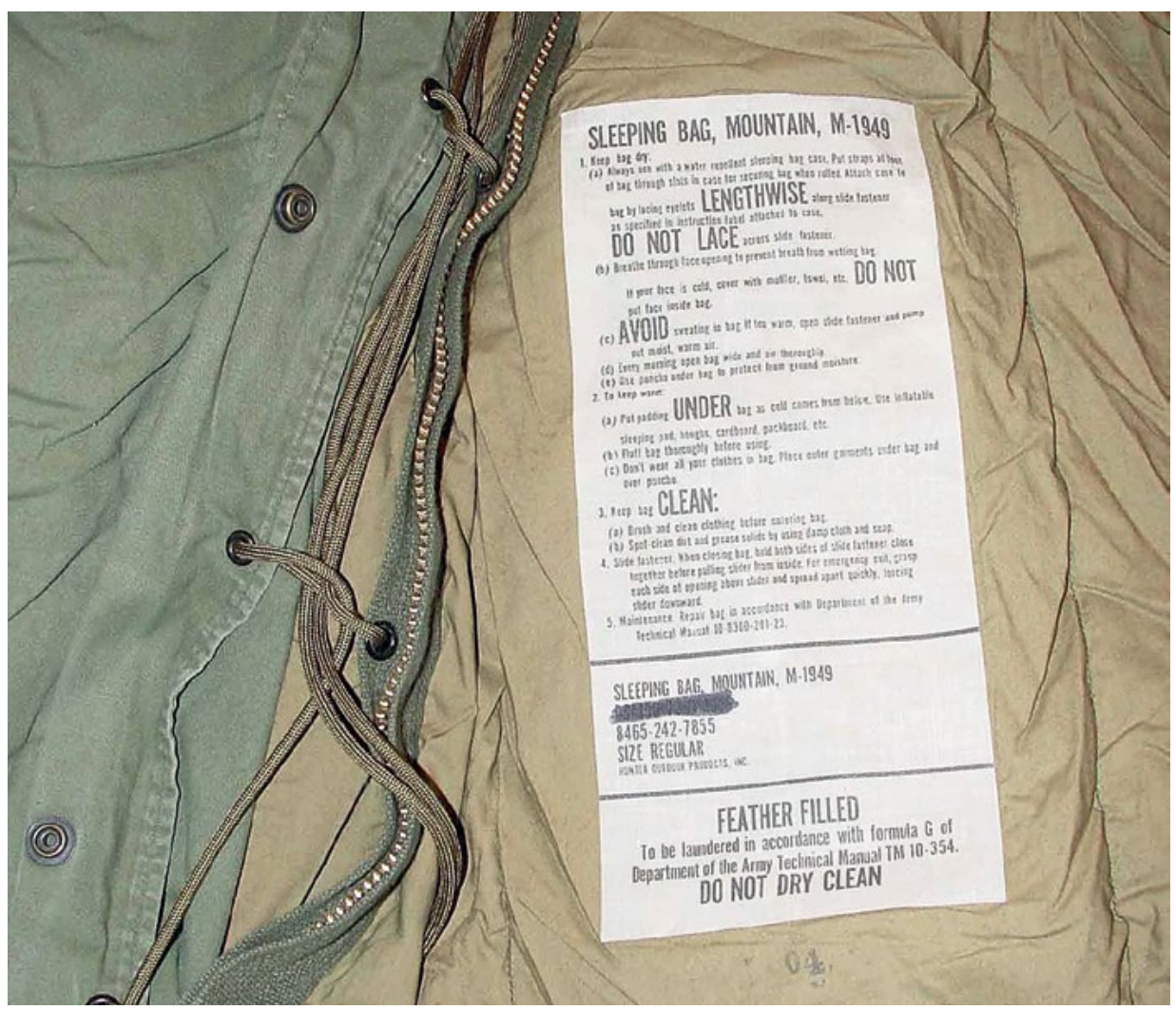

Figure 4. Mountain M-1949, label Photo: Courtesy 1998 Olive-Drab.com LLC 
The technological advances in thermal protective sleeping systems indicate a transformation in thinking about shelter in the landscape. Whereas felt and reindeer fur are materials that are symbiotically connected to the landscape, in that they originate from the very livestock that can sustain life in certain environmental conditions, and in so doing, provide shelter to others, the massmanufactured and synthetically produced sleeping-bag of the nineteenth century reshapes the identity of the landscape. As a material resource, the sleepingbag becomes a travelling marker distanced from the terrain it seeks to occupy. Furthermore, the sleeping-bag system, as appropriated by Western culture for the purposes of exploration, is capable of turning on the user. The Antarctic examples show how a cultural misunderstanding of traditional sleeping-bag technologies can become a destructive agent. The user is not the expert maker anymore and, as a result of conflict, such as war, the form of the sleepingbag has changed. Technological development and the mass production of the sleeping-bag is not the result of relatively benign human activity, such as sheep herding, but an outcome of the military funding that develops scientific laboratories for material experimentation. The global army of sleeping-bags that were manufactured during the Second World War and into the Cold War is an instance of the user's distance from another kind of production process. The body's circulatory system, whether sweating or breathing, is a protective mechanism that the sleeping-bag can obstruct. The soldier has no choice but to passively follow its instructions for use.

\section{The internal structure of the sleeping-bag as a landscape terrain}

The two previous sections have positioned the sleeping-bag by locating material examples derived from and distanced from the landscape. The examples have brought into play a juxtaposition of moments, gathered across time and space, that act as signposts or place holders for some of the histories (factual and semifictional) the sleeping-bag embodies. In returning to our preliminary account of the sleeping-bag as an object of analysis and to the ways in which this shapes a conceptual identity for craft practices, it is necessary to detour into the terrain of the sleeping-bag itself, as a landscape, with a view to establishing the symbolic significance of its internal structure.

In 1970, Philip Leider, then editor of Art Forum, published a short text entitled 'How I spent my summer vacation or, art and politics in Nevada, Berkeley, San Francisco and Utah' (Leider 2009). The piece recalls a visit to see Michael Heizer's Double negative, a land-art construction located in the Moapa Valley, Overton, Nevada. Completed in 1969, it is an excavated trench, measuring 457 metres long, 9 metres wide and 15 metres deep. The negative space of the work involved the displacement of over 244,000 tons of material and is a marker of a gaping hole within the landscape. Leider describes the piece as follows: 
We were all expecting something strong, but none of us were quite prepared for it, as it turned out. We were all yipping and yowling as if Matisse has just called us over to look at something he was thinking of calling Joy of Life. The sun was down; we wound up slipping and sliding inside the piece in the dark. The piece was huge, but its scale was not. It took its place in nature in the most modest and unassuming manner, the quiet participation of a man-made shape in a particular configuration of valley, ravine, mesa and sky. (2009: 535)

Like many creative earthworks of the late 1960s and 1970s, extraction and displacement of materials sought to manifest the convergences between art and landscape. Often executed as rejections of the commercial pursuits of the American art world in the 1960s, they inhabit isolated spaces, transforming over time into new formations. Heizer's deliberate dissection of the Nevada desert through this extraction process reveals the sedimentation of sandstone layers, exposing the landscape's interior structure and material traces of its geological formation. The sleeping-bag, as an object of analysis, also has an internal structure that lends itself to a land-art analogy, for to consider it as if it were a landscape in its own right, enables an imaginary leap into the very space that is in and of itself. This allows the reader to travel inside the sleeping-bag to observe its material construction.

Sales material for contemporary, thermally insulated sleeping-bags is often accompanied by diagrams that show the way in which air circulates through the material to visually express the way in which heat is generated by activity inside the sleeping-bag. As dissections, these diagrams resemble Heizer's earthworks. The analogical leap of the imagination, to firstly position oneself inside Double negative to observe its scale, and to secondly take this experience of size and project it into the diagrammatic space of the sleeping-bag, is part of the journey towards understanding this cocoon-like pod as a travelling concept. As Meike Bal suggests, with reference to the 'concept', one must attempt to give an account of its history, to reflect upon how it has been previously defined, to check its etymological roots and the theoretical contexts that may have informed its understanding by others. She writes:

[W]hile groping to define, provisionally and partly, what a particular concept may mean, we gain insight into what it can do. It is in the grouping that the valuable work lies ... The grouping is a collective endeavour. (2002: 11)

Perhaps the endeavour here, within the space of this essay, is an attempt to find out what a sleeping-bag can do, to us, when we treat it as if it were a concept, that is, an abstract idea, derived from the material of its own making and reception in different contexts. There are two basic definitions of conceptual thinking that need to be signposted before considering what the sleeping-bag can do as a travelling concept. The first concerns mental representations and 
the second, abilities. These definitions are best explained with reference to the internal structure of the sleeping-bag, which is diagrammatically expressed in Figure 5.

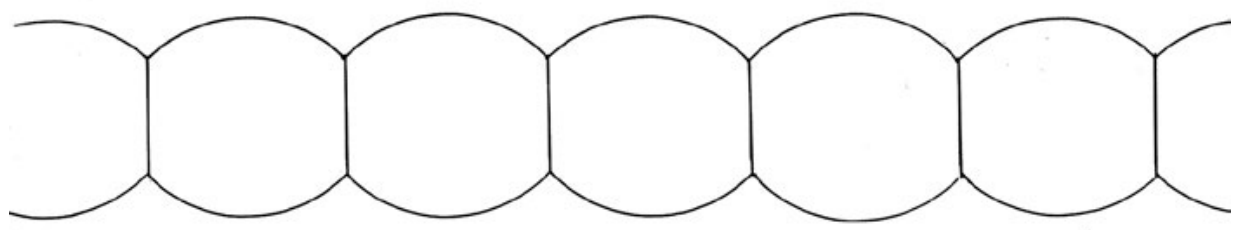

Figure 5. Internal cross-section of a sleeping-bag demonstrating the standard type of box-wall baffle used to hold natural down or synthetic fibre insulation in position Image: Claire Barber

On the one hand, mental constructs allow for the invisible or not-yet-seen to be imagined. Cognition requires the imagination to think beyond the limits of literal understanding. One could say that, on first glance, a diagram of a dissected sleeping-bag is just that. But a diagram is already a mental image, an abstraction or simplified representation of a more complex internal structure. The image becomes a kind of geometric visualisation of a landscape because its purpose is to encapsulate the whole in such a way that it can be computed in the mind. The leap inside the diagram as if it were a landscape, akin to Michael Heizer's Double negative, allows for the sleeping-bag to be understood beyond the formal language of construction. Its internal structure has a circulation system, derived from body heat, and the implications of this relationship suggest that the sleeping-bag develops its own agency, produced from the landscape from which it grows; that is, our own thermal heat system. Abilities, on the other hand, are the skills we learn to enable us to carry out specific tasks. Treating concepts as abilities takes us to craft skills and the thinking capacity of the maker to perform certain activities, mindfully, and with care. Being inside the landscape of materials, where we automatically witness their complex structure and organisation, is the foundation for the specificities of experience. This gives place to the possibility of making sense of the empathic structures of making, particularly when the sleeping-bag as a concept provides an opportunity to change how one thinks through craft-making. This soft theoretical positioning has an impact when it enters into the space of craft practice. Our final example is the manifestation of an alternative narrative of understanding, derived not from where the sleeping-bag appears in space and time, but how it is serves as a place holder for the maker. 


\section{The Sleeping-bag Project}

The Sleeping-bag Project involves different modes of engagement, both inside and outside of the academic institution. Its life began in 2010 in a module on an undergraduate textile craft program at the University of Huddersfield, called 'Crafting the community'. Students practiced different community-centred approaches to volunteering by getting involved in or setting up local community projects, often working alongside economically, socially and/or culturally isolated and under-represented people. Working in collaboration with the curator and volunteer June Hill and Inn Churches Homeless Shelter manager Julie Thompson, the project involves collaborative making by salvaging discarded sleeping-bags from music festivals, laundering them, investing them with textile embellishments and then giving them to the homeless. By recharging these sleeping-bags with a new purpose, these modest material interventions are geographical displacements where aesthetic and political considerations overlap, resulting in the convergence of philosophies of practice and pedagogical ambitions. Often gradual and evolving, each volunteer's perspective on the ethics of care was experienced through the act of crafting something for someone they were never likely to meet. These intimate and personal experiences of engagement were carried through a practice that often stood outside of the artist's studio or classroom context. By encountering differing notions of otherness, hidden or invisible to the face of institutional life, volunteers were able to think with and through a set of themes or questions around the issue of homelessness. The sleeping-bag became an abstract object situated between the maker and an idea of homelessness. By standing in as a material landscape of imaginary possibilities, the sleeping-bag served as a place holder for meaningful activity.

Anyone who chooses to enter the space of The Sleeping-bag Project to issue a response, participates in the processes of 'ethical engagement'. An everevolving play of voices situates and positions the project within a 'politics of care' and this is what ensures its survival. To be homeless is to be without the certainty of belonging to a place. An empathic politics of care does not claim to know this experience. It is rather like a metapractice that takes place through the act of making itself; a form of thinking through the specifics of the task at hand. Those who make a contribution know very well that they can never fully salvage or solve the problem of homelessness. But this is also its potential: ethical interventions begin their life with the very smallest of empathic gestures. The sewing of a pocket into freshly laundered sleeping-bag material, using embroidery to embellish personal messages, holding conversations with oneself or with others about what it might be like to be on the streets, or using a needle and thread to think outside the limits of one's own environment, are gestures that explore the intertwined relationships between feeling and thinking through the landscape of craft. 
This travelling concept began in a field, on which a music festival had recently taken place, in the late summer of 2010. On entering the site, volunteers were confronted by a mass of detritus. Thousands of pop up tents were caught in the breeze and intermittently floated into the air, bobbing down onto the grassland. Inside the tents were traces of human existence hurriedly abandoned: remnants of cosmetics, disposable wipes, rolled sleeping mats and bedding were strewn in an intimate snapshot of unselfconscious scruffiness. Volunteers waded through the waste, routinely unzipping tents in search of sleeping-bags that were not soiled or damaged by fire (see Figure 6).

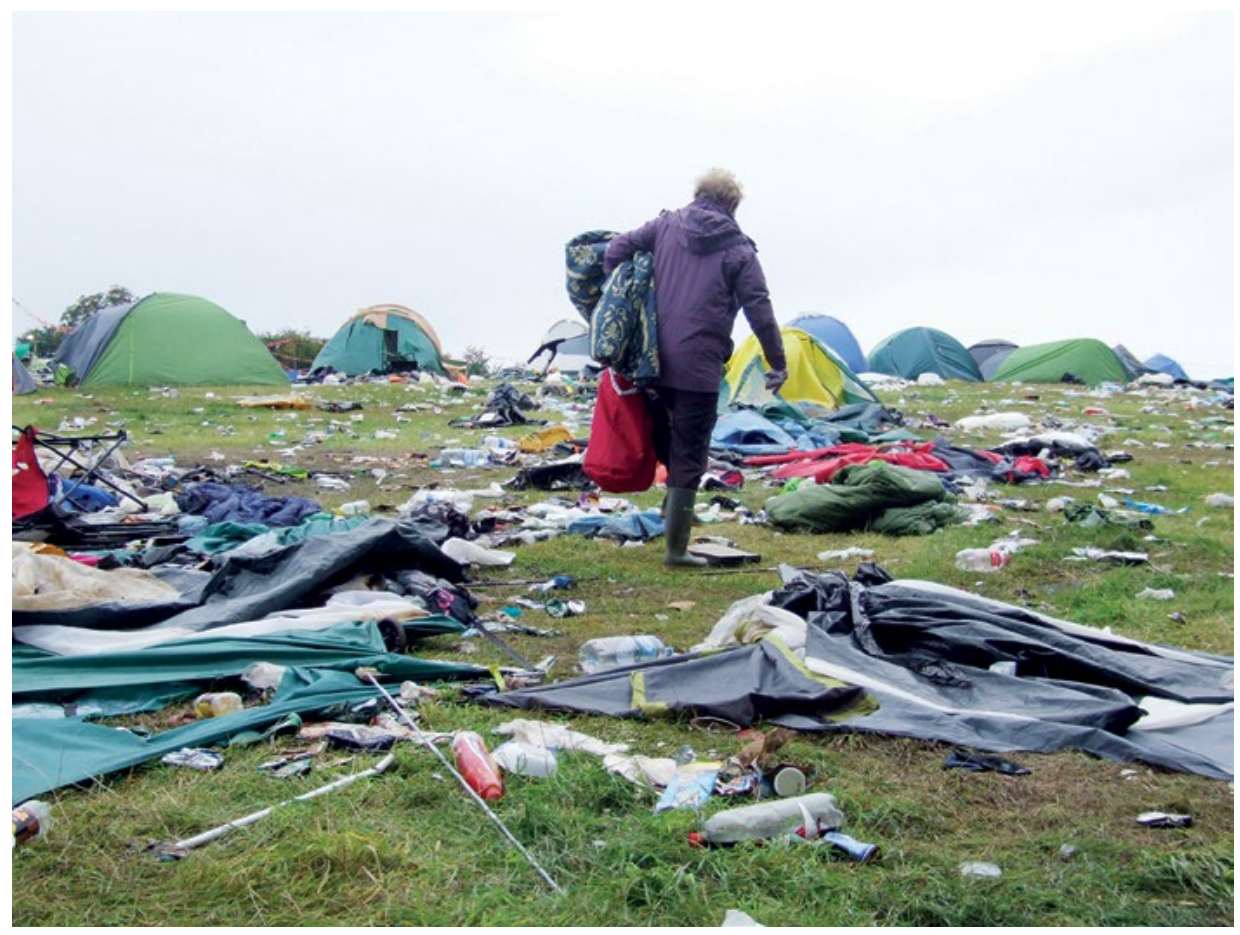

Figure 6. Salvaging discarded sleeping-bags from the aftermath of Leeds Music Festival, 2010

Photo: Claire Barber

These sleeping-bags were bundled into car boots and cascaded into people's homes to be laundered and dried. The venture became a collective process requiring effort and commitment among other weekly washing routines. For instance, one volunteer recalls how she rushed to get sleeping-bags washed and dried amidst the pressures of Christmas and her university deadlines. She carried them by train to her family home and, as sleeping-bags were hung on radiators and draped and arranged in the family living room to dry, she recognised the strain they were causing in her busy household. Another volunteer took a garbage bag filled with sleeping-bags to be washed at her halls of residence and recoiled at the aroma they released: a fierce smoky 
smell, powerfully indicative of where the sleeping-bags had been used. Another volunteer dried sleeping-bags in the shared garden of her Yorkshire terrace home. Hung in rows, creating waves of brightly coloured shapes that echo the rugged hillside backdrop, they brought about conversations with neighbours on the nature of homelessness (see Figure 7). The ongoing project spills into the local community through a social process. One volunteer declared that 'by bringing a sleeping-bag into your home you are also bringing in the very person who will use it'.

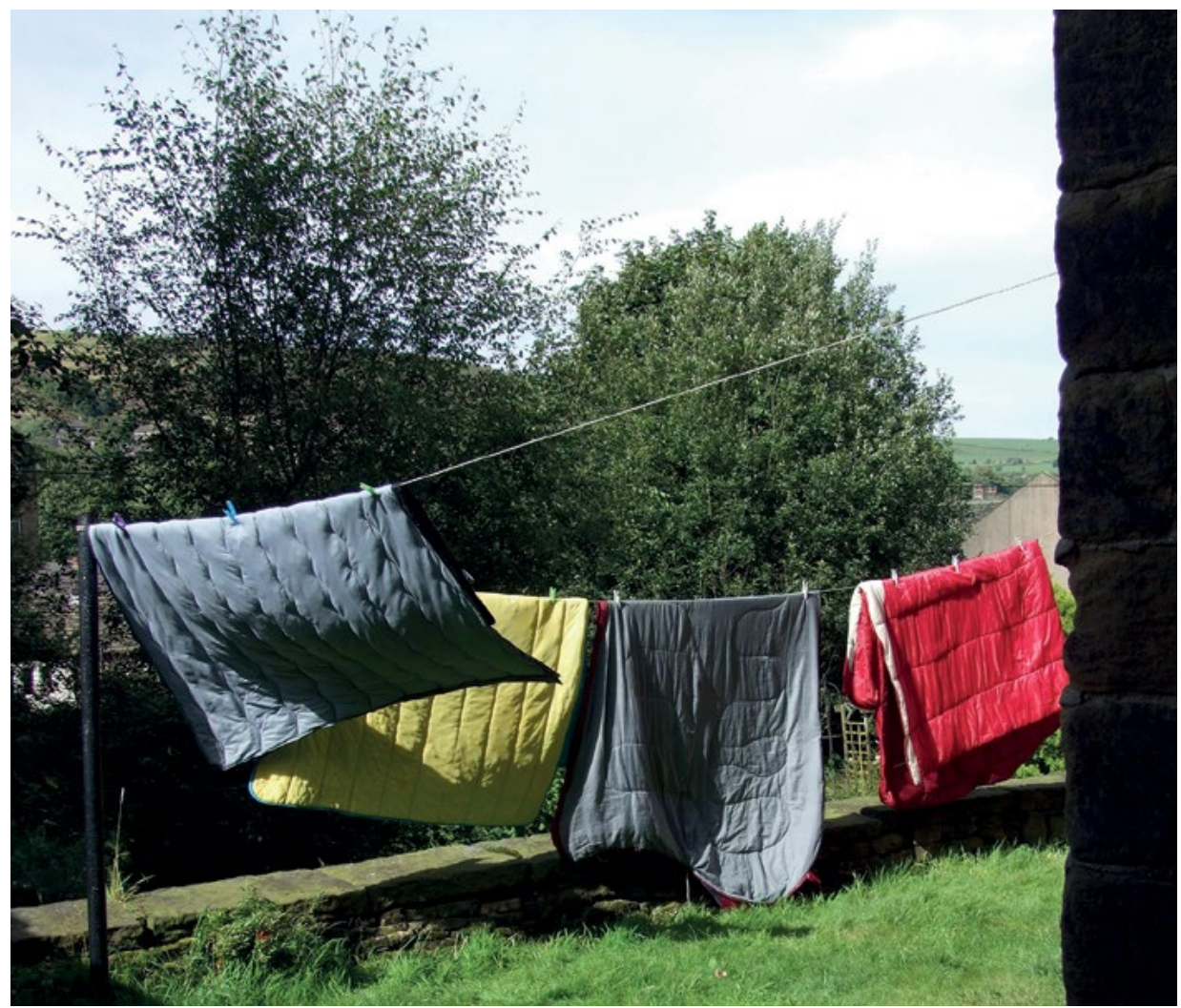

Figure 7. Drying sleeping-bags salvaged from Leeds Music Festival, 2010

Photo: Claire Barber

Adding gestures of care to the sleeping-bag through hand-crafted textile practice, draws upon the abilities of the maker's response. An embroiderer, for example, investigated the material of the sleeping-bag with curiosity as if it were an unexplored terrain. As her needle pierced the slippery mass-produced fabric, she became aware that her stitches would compress the synthetic filling, thereby inhibiting the sleeping-bag's insulating properties. Various alternatives were considered to overcome this problem. It is in this process of exploration that the embroiderer is mindful of the potential end-user, while developing a more in-depth understanding of her own work. 


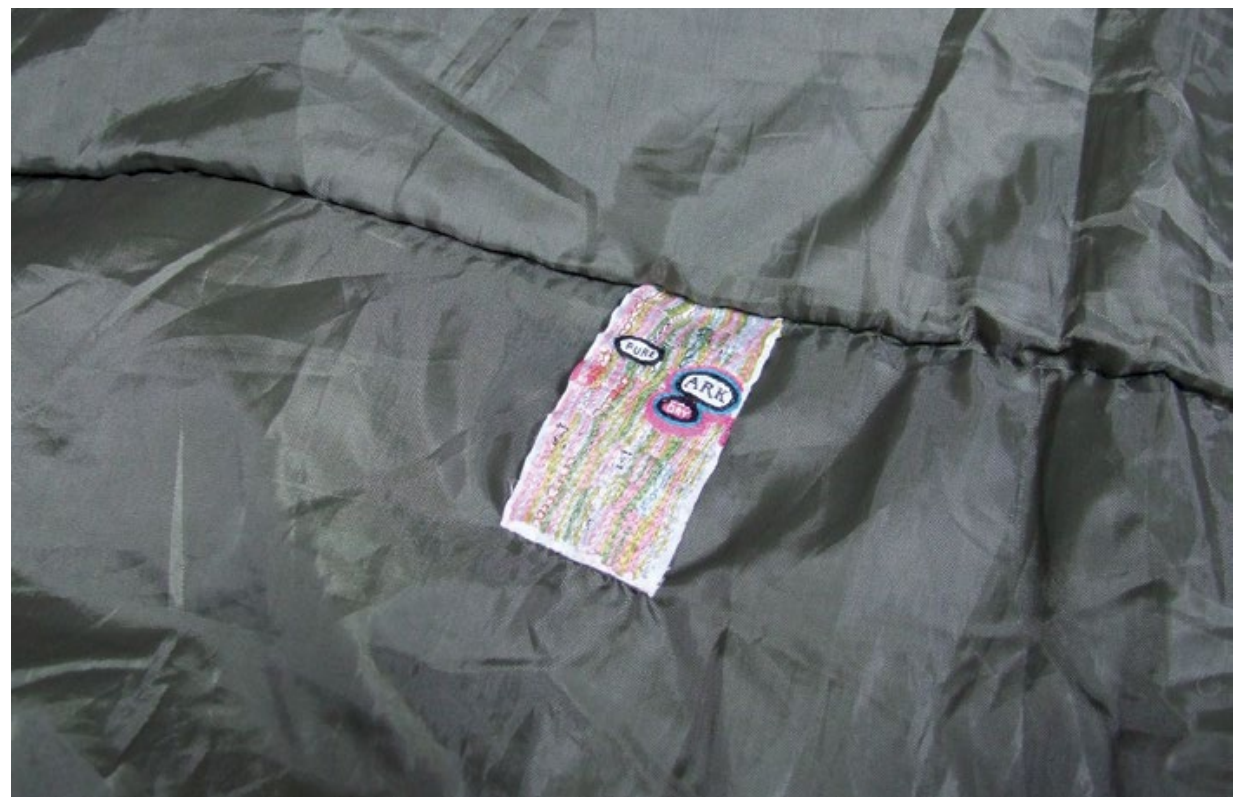

Figure 8. Customising sleeping-bags salvaged from Leeds Music Festival, 2010 Photo: Claire Barber

A weaver used her knowledge of traditional craft techniques to respond to the challenge of how users can transport the unwieldy sleeping-bags, which have often lost their carry bag, when they are not being used as shelter. She developed soft handwoven straps made from weft threads recycled out of disused sleeping mats. This technique creates a soft, strong and compressible strap in bright orange, turquoise and yellow. She asked her friends to test the straps and to experience the feeling of carrying a sleeping-bag slung over their shoulders. Another volunteer considered the challenge of keeping personal belongings safe while asleep outdoors. She developed a passport-sized pocket that is neatly sewn into the inside of the sleeping-bag lining. The pocket was designed to be secured by a looped buttonhole stitch, which is a skilful and time-consuming technique. On realising that she could not finish the pockets in time for the winter shelter, other volunteers helped her out, and met in university corridors between classes to craft the pockets.

It could be seen that craft is irrelevant in the severity of the situation of homelessness. It is tempting to bypass the act of making to arrive at the problem more quickly with a charitable donation. The Sleeping-bag Project, however, implies an extended duality that presents both the functionality of a warm clean space to sleep in and the counterbalance of a craft that is a subtle manifestation of a proof of care between maker and homeless recipient. Cloth is activated by the different levels of interaction: from the transmission of the smell of laundry powder to the carefully hand-sewn buttonhole stitch that secures a pocket for a few personal possessions. 
To conclude, the examples we have discussed provide a way into the social world of the sleeping-bag as a travelling concept. Contained and embedded within each example are the histories and memories of the landscapes that have passed us by and those that continue to mark their presence in contemporary culture. Arriving at a condition of empathy with The Sleeping-bag Project offers up a very different approach to craft-making. As a case study, it articulates how the sleeping-bag is a necessary segue between the maker and the user or, in the language of the process of empathic identification, between the mental and affective capacity to put oneself into the place of the other. The ethical issues associated with this kind of leap, as if one can truly incorporate the specificities of the other's experience, should be noted. We are aware of the risk of this becoming another form of isolation at the level of a mental appropriation. When considered in the wider context of the sleeping-bag landscape, however, the reader is invited to consider the terrain, context and complexities of conditions of living, through a mode of abstraction that takes the wider landscapes of material life experience into consideration. The diagrammatic abstraction of the sleeping-bag allows us to linger in the space of homelessness rather than through the personal and private space of the displaced person. This encourages further consideration of the wider historical, political, economic and social factors that make up the condition of homelessness. This is similar to the imaginary empathic investment of the maker who, through their acts of doing, reconfigures the reception of the historical examples mentioned above. In effect, the making activity of the craftsperson brings the reader closer to what the sleeping-bag can offer as a travelling concept. Its life is activated as one develops the slow process of crafting an intimate relationship to the material qualities of cloth. Mental representations, craft abilities and abstractions derived from thinking with and through the sleeping-bag is what gives it its currency as a concept. Homelessness, the abstract concept, is thus carried by the sleepingbag into the space of the maker and, for a moment, the complex particularities of a real-world experience linger in the mental imaginary of the needle worker.

Claire Barber is an artist and senior lecturer in textiles at the University of Huddersfield. Her exposure to textiles impacts on her approach to community contexts and she often works in socially engaged forms.

Rowan Bailey is a senior lecturer in Historical and Theoretical Studies and Postgraduate Taught Coordinator at the University of Huddersfield. She is currently exploring practitioner approaches to archives and existing art collections. 


\section{References}

Bal, M., 2002, Travelling Concepts, University of Toronto Press.

Belgrave, A., 2001, How to Make Felt, Tunbridge Wells, Kent: Search Press Ltd.

British Museum and BBC, 2010, 'The Euklisia rug', A History of the World, viewed 29 June 2014, www.bbc.co.uk/ahistoryoftheworld/ objects/3cdTqQBDTBGmTAMBWxITQA.

Burkett, M., 1971, The Turcoman of Iran, Kendal: Abbot Hall Art Gallery.

Cherry-Garrard, A., 1989 (1922), The Worst Journey In the World: Antarctica, London: Carroll \& Graf.

Deffontaines, P. (ed.), 1967, Larousse Encyclopaedia of the World, London: Paul Hamlyn Press.

Jurries, A., 2013, 'Nemo Canon-40 Sleeping Bag', 31 January, viewed 23 August 2015, www.thegearcaster.com/2013/01/nemo-canon-40sleeping-bag.html?utm_source=feedburner\&utm_medium=feed\&utm_cam paign=Feed $\% 3 A+$ TheGearcaster+(the+GearCaster).

Leider, P., 1970, 'How I spent my summer vacation or, art and politics in Nevada, Berkeley, San Francisco and Utah', in Glenn Adamson (ed.), The Craft Reader, Oxford: Berg, 2009, pp. 534-39.

Scott of the Antarctic, 1948, London: Ealing Studios.

Startzman, E., 2014, 'A brief history of sleeping-bags', EzineArticles, 21 January, viewed 29 June 2014, ezinearticles.com/?A-Brief-History-of-SleepingBags\&id=8266462. 
This text is taken from Craft + Design Enquiry, Issue 7, 2015, edited by Kay Lawrence, published 2015 by ANU Press, The Australian National University, Canberra, Australia. 